\title{
Two Modes of Vesicle Recycling in the Rat Calyx of Held
}

\author{
R. P. J. de Lange, ${ }^{1}$ A. D. G. de Roos, ${ }^{2}$ and J. G. G. Borst ${ }^{1}$ \\ ${ }^{1}$ Department of Neuroscience, Erasmus MC, University Medical Center, 3000 DR Rotterdam, The Netherlands, and ${ }^{2}$ Swammerdam Institute for Life \\ Sciences, University of Amsterdam, 1098 SM Amsterdam, The Netherlands
}

Vesicle recycling was studied in the rat calyx of Held, a giant brainstem terminal involved in sound localization. Stimulation of brain slices containing the calyx-type synapse with a high extracellular potassium ion concentration in the presence of horseradish peroxidase resulted within several minutes in a reduction of the number of neurotransmitter vesicles and in the appearance of labeled endosome-like structures. After returning to normal solution, the endosome-like structures disappeared over a period of several minutes, whereas simultaneously the number of labeled vesicles increased. A comparison with afferent stimulation suggested that the endosome-like structures normally do not participate in the vesicle cycle. Afferent stimulation at $5 \mathrm{~Hz}$ resulted in sustained synaptic transmission, without vesicle depletion but with an estimated endocytotic activity of $<0.2$ synaptic vesicles per active zone per second. At $20 \mathrm{~Hz}$, the presynaptic action potentials generally failed during prolonged stimulation. In identified synapses, the number of vesicles labeled by photoconversion after stimulation at $5 \mathrm{~Hz}$ in the presence of the styryl dye RH414 was much lower than the number of vesicles that were released, as determined by measuring EPSCs. No more than $\sim 5 \%$ of the vesicles were labeled after 20 min stimulation at $5 \mathrm{~Hz}$, whereas this stimulation protocol was sufficient to largely destain a terminal after previous loading.

The results support a scheme for recycling in which two different modes coexist. At physiological demands, a pool of $\sim 5 \%$ of all vesicles provides sufficient vesicles for release. During intense stimulation, such as occurs in the presence of high extracellular $\mathrm{K}^{+}$, the synapse resorts to bulk endocytosis, a very slow mode of recycling.

Key words: presynaptic; vesicle cycle; readily releasable pool; photoconversion; ultrastructure; styryl dye; EPSC

\section{Introduction}

Within synaptic terminals, different physiologically defined pools of synaptic vesicles (SVs) can be discriminated on the basis of kinetic differences in their release properties. The pool that has been studied in most detail is the readily releasable pool (RRP), typically defined as the set of vesicles that are immediately available for release. At the calyx of Held, a giant terminal in the auditory brainstem, this pool is estimated to contain 600-6000 vesicles in young rats, depending on the exact definition and the method used to probe this pool (Schneggenburger et al., 2002). During high-frequency stimulation, the RRP may be rapidly depleted, leading to a depression of the synaptic responses (von Gersdorff and Borst, 2002). To sustain synaptic transmission, a fast mechanism for replenishment of the vesicles released from the RRP is therefore essential. The RRP may draw on the so-called reserve pool of vesicles for replenishment. Together these two

Received July 17, 2003; revised Sept. 18, 2003; accepted Sept. 19, 2003.

This study was supported by a Pionier Netherlands Organization for Scientific Research and a Human Frontier Science Program grant to J.G.G.B. We thank F. van Krevelen of the Swammerdam Institute for Life Sciences (SILS) for designing and building a biphasic current stimulator, Dr. Norbert Vischer (SILS) for writing Object Image macros to do geometric analysis, vesicle distribution, and density analysis, Dr. Paul Mulder (Department of Epidemiology and Biostatistics, Erasmus MC) for statistical advice and for performing the mixed-model ANOVA, Hilco Theeuwes (Erasmus MC) for assistance with electron microscopy, and Dr. Wim van Raamsdonk (SILS) for the use of his fluorescence setup.

Correspondence should be addressed to Dr. Gerard Borst, Department of Neuroscience, Erasmus MC, University Medical Center Rotterdam, P.0. Box 1738, 3000 DR Rotterdam, The Netherlands. E-mail: g.borst@erasmusmc.nl.

R. P. J. de Lange's present address: Rudolph Magnus Institute for Neurosciences, P.0. Box 800400, 3508 TA Utrecht, The Netherlands.

Copyright $\odot 2003$ Society for Neuroscience 0270-6474/03/2310164-10\$15.00/0 constitute the recycling pool, the vesicles that participate in the exo-endocytotic cycle. In cultured hippocampal neurons, on average only $\sim 30$ of the 200 vesicles present, or $15 \%$, can be shown to be part of the recycling pool (Harata et al., 2001b). The remaining $85 \%$ of vesicles seemingly not partaking in synaptic transmission form the so-called resting pool. If only a small minority of synaptic vesicles are recycling competent, it follows that the reserve pool may also be rapidly depleted under circumstances of high-frequency synaptic transmission. Therefore, the speed of the exo-endocytotic cycle ultimately determines the maximum information-carrying capacity of synapses during longer periods of stimulation. Information about the speed at which the different pools may interact is therefore of interest to determine the adaptations to the demand imposed by the different circumstances. At least two different pathways of endocytosis have been described: one in which vesicles directly bud off from the presynaptic membrane and another in which vesicles are formed from an endosome-like intermediate (Koenig and Ikeda, 1996; Takei et al., 1996; Richards et al., 2000; Teng and Wilkinson, 2000). The relative importance of these pathways is still debated.

Here we have studied the regulation of different vesicle pools at the calyx of Held terminal in slices of the rat brainstem. The large size of the calyx of Held allowed us to study the relation between synaptic vesicle release and recycling within the same, single, identified, central mammalian synapse. Vesicle pools were studied optophysiologically using fluorescent membrane styryl dyes. We compared labeling of vesicles and endosomal intermediates during stimulation with high potassium solution and during afferent stimulation. In addition, we applied photoconver- 
sion of these fluorescent dyes to visualize the labeled vesicle pools with electron microscopy (EM), complementing data from experiments in which horseradish peroxidase (HRP) was used as a recycling marker.

\section{Materials and Methods}

Brain slices. Six- to 10-d-old Wistar rats were decapitated without previous anesthesia, in accordance with national guidelines. Transverse brainstem slices $(200 \mu \mathrm{m})$ were cut with a vibratome in ice-cold saline containing (in mM): $125 \mathrm{NaCl}, 2.5 \mathrm{KCl}, 3 \mathrm{MgCl}_{2}, 0.1 \mathrm{CaCl}_{2}, 1.25 \mathrm{NaH}_{2} \mathrm{PO}_{4}$, 0.4 ascorbic acid, 3 myo-inositol, 2 Na-pyruvate, $25 \mathrm{D}$-glucose, and 25 $\mathrm{NaHCO}_{3}$ and maintained at $\mathrm{pH} 7.4$ by bubbling with $5 \% \mathrm{CO}_{2} / 95 \% \mathrm{O}_{2}$. After cutting, slices were transferred to a Ringer's solution containing (in mm): $125 \mathrm{NaCl}, 2.5 \mathrm{KCl}, 1 \mathrm{MgSO}_{4}, 2 \mathrm{CaCl}_{2}, 1.25 \mathrm{NaH}_{2} \mathrm{PO}_{4}, 0.4$ ascorbic acid, 3 myo-inositol, $2 \mathrm{Na}$-pyruvate, 25 D-glucose, and $25 \mathrm{NaHCO}_{3}, \mathrm{pH}$ 7.4 with $5 \% \mathrm{CO}_{2} / 95 \% \mathrm{O}_{2}$, and incubated for $30 \mathrm{~min}$ at $37^{\circ} \mathrm{C}$. Afterward, slices were kept at room temperature $\left(22-25^{\circ} \mathrm{C}\right)$.

Electrophysiology. Postsynaptic pipettes (4-6 $\mathrm{M} \Omega$ ) were filled with a solution containing (in $\mathrm{mM}$ ): $125 \mathrm{~K}$-gluconate, $20 \mathrm{KCl}, 10 \mathrm{Na}_{2}$ phosphocreatine, $4 \mathrm{MgATP}, 0.3 \mathrm{Na}_{2} \mathrm{GTP}$, 0.5 EGTA, and $10 \mathrm{HEPES}, \mathrm{pH}$ 7.2 with $\mathrm{KOH}$. When NMDA currents were studied, $\mathrm{K}^{+}$in the intracellular pipette solution was replaced with equimolar $\mathrm{Cs}^{+}$. Postsynaptic whole-cell currents were acquired using an AxoPatch 200B amplifier (Axon Instruments, Union City, CA). Postsynaptic series resistances (typically $10-14 \mathrm{M} \Omega$ ) were compensated to $90-95 \%$. Potentials were corrected for a liquid junction potential of $-11 \mathrm{mV}$. EPSCs were filtered at $5 \mathrm{kHz}$ and digitized at $20 \mathrm{kHz}$ with a 16-bit analog-to-digital converter (Digidata 1320A, Axon Instruments).

Synapses in the medial nucleus of the trapezoid body (MNTB) were afferently stimulated by biphasic current injection with an extracellular bipolar current electrode (FHC, Bowdoinham, ME) placed at the midline. While recording with an extracellular pipette, synapses were preselected with a delay between presynaptic and postsynaptic signals of $<4$ $\mathrm{msec}$, without postsynaptic failures at a stimulation frequency of $0.5 \mathrm{~Hz}$. Postsynaptic whole-cell recordings were not included for analysis when either the series resistance was $>15 \mathrm{M} \Omega$ or the membrane resistance was $<90 \mathrm{M} \Omega$.

Quantal content was measured as the ratio between the amplitudes of evoked EPSCs and spontaneous EPSCs, which were assumed to be $40 \mathrm{pA}$, in agreement with earlier results (Borst and Sakmann, 1996) and with the measured amplitudes in a subset of the destaining experiments.

To test the effect of the NMDA receptor antagonist MK-801 (5 $\mu \mathrm{M})$ (Sigma, St. Louis, MO) on release probability, slices were preincubated for $\sim 3 \mathrm{~min}$ in the presence of the drug in the absence of afferent stimulation. Ringer's solution was circulated continuously using a pump; total volume of the solution was $10 \mathrm{ml}$.

Fluorescence microscopy. Synaptic vesicles were labeled by inducing synaptic vesicle recycling by afferent stimulation (see above) or by depolarizing the terminals in HEPES-buffered ( $25 \mathrm{~mm}, \mathrm{pH}$ 7.4) Ringer's solution in which $55 \mathrm{~mm} \mathrm{Na}^{+}$was replaced by potassium ions ("high $\mathrm{K}^{+}$ solution"), in the presence of the styryl dyes RH414 (100 $\mu \mathrm{M})$ or FM1-43 (10 $\mu \mathrm{M}$; both from Molecular Probes, Eugene, OR). For destaining experiments at $5 \mathrm{~Hz}$, slices were labeled in high $\mathrm{K}^{+}$solution $(2-3 \mathrm{~min} ; n=$ 2 ) or by afferent stimulation ( $5 \mathrm{~min}$ at $5 \mathrm{~Hz} ; n=10)$. For destaining experiments at $20 \mathrm{~Hz}$, slices were labeled with high $\mathrm{K}^{+}$solution $(2-3$ min; $n=5$ ). After labeling, slices were placed in Ringer's solution containing $0.5 \mathrm{mg} / \mathrm{ml}$ of the sulfobutyl ether $\beta$-cyclodextrin (Advasep; CyDex, Overland Park, KS) for 20-60 min to reduce background staining (Kay et al., 1999). Control experiments showed no effect of Advasep on transmission. RH414 and FM1-43 were excited by a halogen lamp (excitation $480 \pm 20 \mathrm{~nm}$; dichroic mirror $505 \mathrm{~nm}$ long pass; emission $510 \mathrm{~nm}$ long pass). Images were taken with a 12-bit cooled CCD camera (SensiCam; PCO, Kelheim, Germany). For photoconversion experiments, slices were labeled for 1, 3, 15, or $30 \mathrm{~min}$ and repolarized in Advasep Ringer's for $30 \mathrm{~min}$ before fixation to estimate the size of the recycling pool (see Fig. 2) or were labeled for $3 \mathrm{~min}$ and then fixed after 0, 10, 20, or 30 min repolarization in Advasep Ringer's to estimate the rate at which SVs are formed from the large endosome-like structures (see Fig. 3).
Identified cells. Postsynaptic cells were identified for electron microscopy by filling them with $0.25 \% \mathrm{HRP}$ via a patch pipette. To preserve the ultrastructure of the synapse as much as possible, postsynaptic whole-cell recordings lasted $<5$ min. They were made before the RH414 labeling procedure. During the labeling procedure, an extracellular patch pipette monitored the presynaptic and postsynaptic action potentials (APs) of the labeled synapse. During the labeling, $10 \mathrm{ml}$ Ringer's containing 100 $\mu \mathrm{M}$ RH414 was circulated using a roller-tube pump.

Labeling with HRP as a fluid-phase endocytosis marker. Brainstem slices were preincubated in HEPES-buffered Ringer's solution containing 10 $\mathrm{mg} / \mathrm{ml} \mathrm{HRP} \mathrm{for} 5 \mathrm{~min}$, to allow for diffusion of HRP into the synaptic clefts, and subsequently depolarized in the presence of $10 \mathrm{mg} / \mathrm{ml} \mathrm{HRP} \mathrm{in}$ high $\mathrm{K}^{+}$solution. After labeling, slices were fixed directly in $2.5 \%$ glutaraldehyde and $1.6 \%$ paraformaldehyde in $0.1 \mathrm{M}$ phosphate buffer (PB) for 30-60 min at room temperature, or returned to HEPES-buffered Ringer's solution for 15,30 , or 60 min before fixation.

Electron microscopy. Photoconversion of styryl dyes was performed largely as described in Richards et al. (2000). After labeling of terminals with fluorescent dyes, slices were fixed in $2.5 \%$ glutaraldehyde and $1.6 \%$ paraformaldehyde in $0.1 \mathrm{M} \mathrm{PB}$ for 30-60 min at room temperature. The slices were then washed two times for $10 \mathrm{~min}$ each in $0.1 \mathrm{M}$ PB containing $0.1 \mathrm{~m}$ glycine (Harata et al., 2001a) and an additional $10 \mathrm{~min}$ in $0.1 \mathrm{M} \mathrm{PB}$. After preincubution for $15 \mathrm{~min}$ in an ice-cold $0.1 \mathrm{M} \mathrm{PB}$ solution that contained diaminobenzidine (DAB) $(1.5 \mathrm{mg} / \mathrm{ml})$, which was bubbled with oxygen, slices were photoconverted under an Olympus IX-70 inverted microscope in the same solution. The fluorescent terminals were illuminated for 20-25 min with a mercury lamp through an Olympus $40 \times(0.35$ numerical aperture) objective, with blue light $(480 \mathrm{~nm})$, while saturating the solution with oxygen, supplied by a continuous flow over the slice, until at least 5 min after all fluorescence had faded and DAB precipitation was clearly visible. A clear $\mathrm{DAB}$ precipitate appeared in the HRP-patched identified cells during the photoconversion, without the need to add $\mathrm{H}_{2} \mathrm{O}_{2}$ to the DAB solution.

After labeling of terminals with HRP, the slices were fixed in $2.5 \%$ glutaraldehyde and $1.6 \%$ paraformaldehyde in $\mathrm{PB}$ for 30-60 min at room temperature, washed two times for 10 min each in $0.1 \mathrm{M} \mathrm{PB}$ containing $0.1 \mathrm{M}$ glycine and an additional $10 \mathrm{~min}$ in $0.1 \mathrm{M} \mathrm{PB}$. They were then transferred to a $3 \mathrm{mg} / \mathrm{ml} \mathrm{DAB}$ solution in $0.1 \mathrm{M} \mathrm{PB}$ for $20 \mathrm{~min}$, after which $\mathrm{H}_{2} \mathrm{O}_{2}$ was added to a final concentration of $0.01 \%$ for $30 \mathrm{~min}$.

After the DAB steps in both the styryl dye and HRP-labeling procedures, the slices were washed at least two times for $10 \mathrm{~min}$ each in $0.1 \mathrm{M}$ $\mathrm{PB}$ and then either postfixed overnight at $4^{\circ} \mathrm{C}$ in the same fixative and washed three times for $10 \mathrm{~min}$ each in $0.1 \mathrm{M} \mathrm{PB}$ the next day or stored overnight in $0.1 \mathrm{M} \mathrm{PB}$ at $4^{\circ} \mathrm{C}$.

Tissue blocks in regions of interest sized $1 \times 1 \mathrm{~mm}$ were cut from the slices and postfixed in $1 \%$ osmium tetroxide in distilled $\mathrm{H}_{2} \mathrm{O}$ and stained en bloc in $1 \%$ uranyl acetate in $\mathrm{H}_{2} \mathrm{O}$. Blocks were then dehydrated and flat embedded in Epon. Semithick $(2 \mu \mathrm{m})$ sections were cut and stained with $1 \%$ methylene blue to determine the region of interest, from which ultrathin $(50-80 \mathrm{~nm})$ sections were cut and collected on Formvarcoated grids. Ultrathin sections were counterstained with uranyl acetate or lead citrate, or both, and examined and photographed with a Philips EM 201 or a Philips CM100 electron microscope. On the EM 201, electron micrographs were made on $35 \mathrm{~mm}$ negative film (Kodak 5312) and were digitized by scanning the film at $1600 \mathrm{dpi}$. The CM 100 microscope was fitted with a CCD camera (Megaview II; Soft Imaging System, Muenster, Germany). The multiple image alignment function of the scan analysis software was used to capture large areas of calyx terminals.

EM image analysis. EM images were analyzed using Object-Image (Vischer et al., 1994), which can be downloaded from http://simon.bio. uva.nl/www/object-image.html. Example object files and macros for synaptic vesicle distribution and synaptic vesicle density analysis may be obtained from the authors. The ultrastructure of the terminals after labeling with HRP or styryl dyes was generally not as good as after perfusion fixation. Typically, three to five calyceal synapses were found in the ultrathin section with acceptable morphology (see Fig. 1); however, although vesicles were clustered in regular patches along the plasma membrane facing the synaptic cleft, almost invariably postsynaptic densities and active zones were hard to identify. Therefore, the relative distribu- 
tion of vesicles was given as the shortest distance to the plasma membrane facing the synaptic cleft in the electron micrographs. Vesicles were assessed to be labeled or not by visual inspection. This method was verified for a limited number of terminals by SV density analysis: the mean gray value of all pixels in a $15 \mathrm{~nm}$ radius from the center of the lumen of the vesicles was measured for designated labeled and unlabelled SVs and plotted as a histogram (see Fig. 1C). A 10\% correction was made for shrinkage of tissue section thickness (to $85 \mathrm{~nm}$ ) when estimating the total number of vesicles.

Fluorescent image analysis. Fluorescent images were analyzed using custom macros written in Igor Pro 4 (WaveMetrics, Lake Oswego, OR). The average fluorescence in a region of interest containing the terminal was measured after subtraction of average fluorescence of a background region. The decrease of fluorescence in the background region over time was used to correct for dye bleaching.

Statistics. Results are given as mean \pm SEM. Because not all cross sections of terminals analyzed were the same size, and it is unclear to what extent osmotic swelling had affected the cytoplasmic area of the terminal in our cross sections, results are generally given as the number of synaptic vesicles relative to the length of the membrane facing the synaptic cleft.

One-way ANOVA was followed by a Newman-Keuls test to test for pairwise treatment differences.

To compare whether the mean distance from the membrane differed between unlabeled and photoconverted vesicles, a mixed-model ANOVA on the log-transformed data was performed. After log transformation, the distribution of distances became Gaussian shaped. In the model, the dependence of the vesicle distances on labeling (positive or negative), duration of the recovery period, and method to evoke release were tested.

Differences in labeling efficiency between vesicle clusters were tested with the $\chi^{2}$ test. Probabilities for significance were corrected for multiple testing according to Bonferroni.

The Pearson correlation coefficient $(r)$ was used to test whether there was a significant linear relationship between two variables (see Figs. 5, 6).

\section{Results}

\section{Total number of vesicles}

For a rough estimate of the total number of vesicles in the calyx of Held, the number of SVs was counted in cross sections from 50 terminals. This number was multiplied by the estimated total volume of the calyx (4.8 pl) (Sätzler et al., 2002) divided by the cross-sectional volume (area $\times$ section thickness, $85 \mathrm{~nm}$ ), yielding $188,000 \pm 8000$ (SEM) SVs.

\section{High $\mathrm{K}^{+}$stimulation}

Size of the recycling pool

To estimate the size of the recycling pool, terminals were stimulated with high $\mathrm{K}^{+}$solution in the presence of the fluorescent styryl membrane dyes RH414 or FM1-43. After fixation, the fluorescence was photoconverted to a permanent signal (Henkel et al., 1996), and the numbers of labeled and unlabelled SVs were counted on cross sections of the terminals at the EM level (Fig. $1 A, B)$. A separation of labeled and unlabeled vesicles emerged, on the basis of their lumenal density (Fig. 1C). From the overlap in the peaks we estimate that $6 \%$ of the SVs in our experiments are misclassified, a value comparable with that in earlier experiments (Harata et al., 2001a; Schikorski and Stevens, 2001). Photoconverted and clear vesicles appeared to be randomly interspersed (Fig. $1 D$ ).

To get an estimate of the maximal possible labeling, we incubated slices for different time periods with high $\mathrm{K}^{+}$solution in the presence of the styryl dyes FM1-43 and RH414 or the fluid phase marker HRP, followed by a rest period in control Ringer's of at least $30 \mathrm{~min}$. Although labeling was variable between experiments, labeling efficiencies for RH414 and FM1-43 were similar within the same experiment $(n=2 ; t$ test; $p>0.05)$. Because HRP
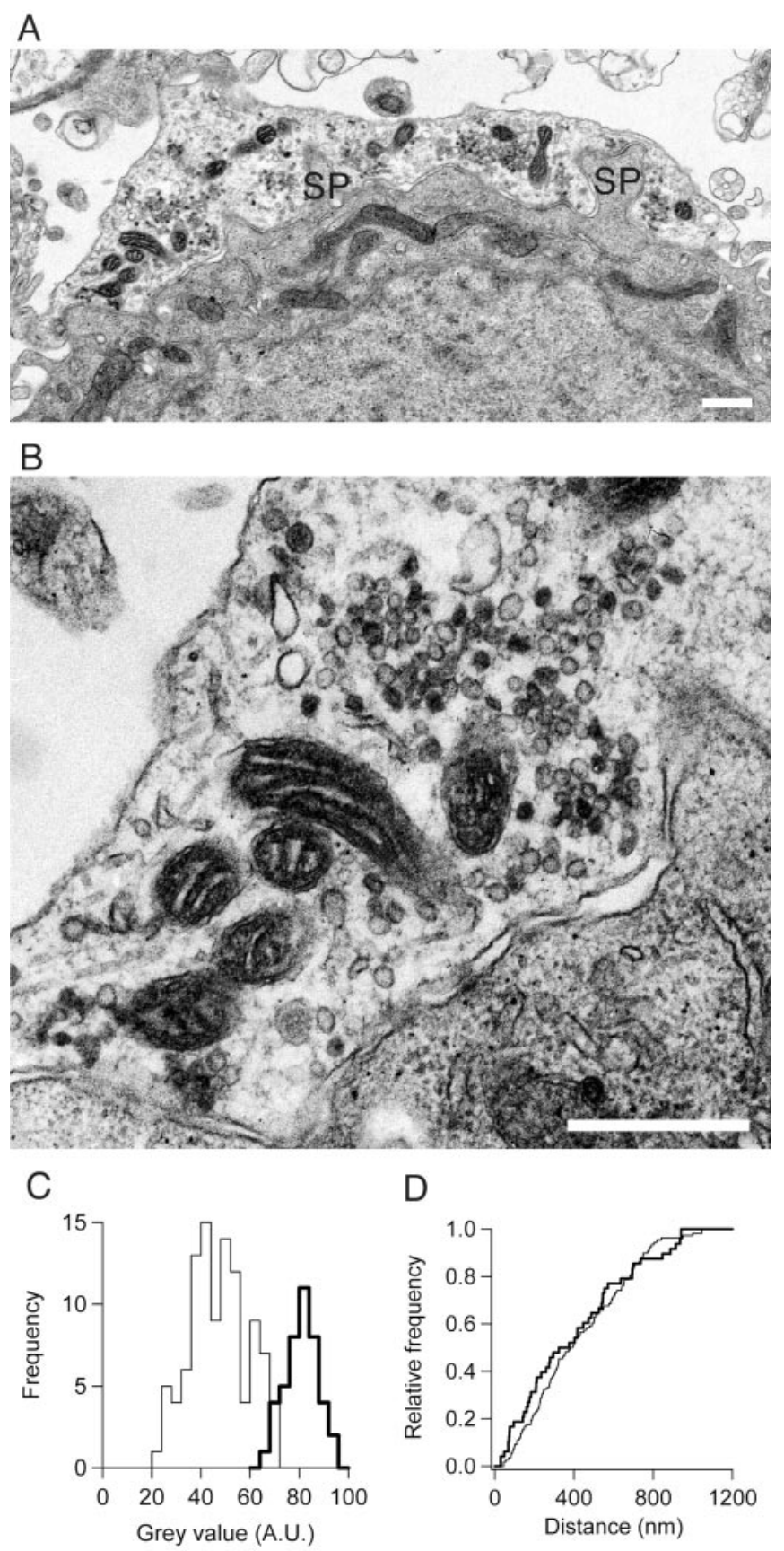

Figure 1. Visualizing vesicle pools in the calyx of Held terminal. A, Example of the ultrastructure of part of a calyx of Held and associated principal cell in the MNTB after photoconversion after a 3 min labeling in high $\mathrm{K}^{+}$solution in the presence of FM1-43. SP, Spine-like protrusion (found in all terminals studied, often surrounded by clusters of synaptic vesicles). Scale bar, 1 $\mu \mathrm{m}$. B, Detail of structure in $A$ showing labeled vesicles containing the black photoconversion precipitate and unlabeled clear vesicles. $C$, Histogram of densities [mean gray value of pixels in a $15 \mathrm{~nm}$ radius from the center of the lumen of the vesicles, plotted in arbitrary units (A.U.)] of vesicles that were labeled as positive (thick line) or negative (thin line), showing difference between photoconverted and control vesicles. D, Cumulative histogram of distances of photoconverted (thick line) and control vesicles (thin line) from the plasma membrane facing the synaptic cleft. $A-D$ are from the same experiment.

also appeared to have similar labeling efficiency as both styryl dyes, the data for HRP, FM1-43, and RH414 were pooled. An increasing number of vesicles were labeled with increasing high $\mathrm{K}^{+}$stimulation duration (Fig. 2). Maximal labeling was achieved after 15 min stimulation $(7.5 \pm 1.5 \mathrm{SV} / \mu \mathrm{m}$ or $40 \pm 6 \%)$; no 


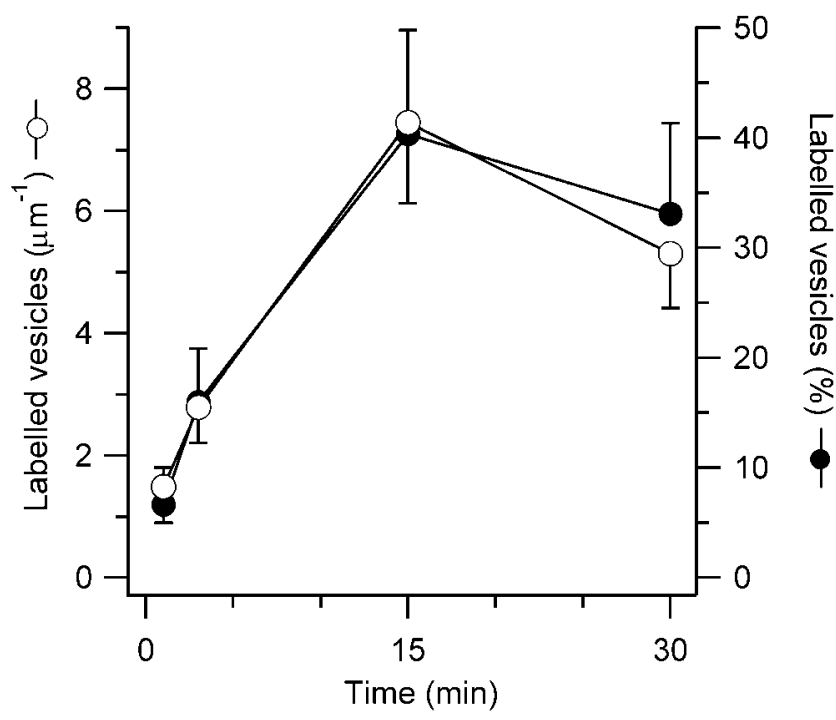

Figure 2. Maximal labeling of terminals. Relation between labeling duration using high $\mathrm{K}^{+}$ stimulation and the number of labeled vesicles per micrometer plasma membrane facing the synaptic cleft (left ordinate) or the percentage of vesicles labeled (right ordinate). Slices were fixed (and photoconverted) after a 30 min rest period in Ringer's solution with Advasep after 1 $\min$ ( $n=4$ animals, 14 terminals), $3 \mathrm{~min}$ ( $n=6$ animals, 19 terminals), $15 \mathrm{~min}$ ( $n=4$ animals, 14 terminals), or $30 \mathrm{~min}$ ( $n=2$ animals, 7 terminals) in high $\mathrm{K}^{+}$stimulation in the presence of FM1-43, RH414, or HRP.

further increase was obtained when slices were incubated for 30 min in high $\mathrm{K}^{+}$solution.

Vesicles are clustered near active zones within the calyx of Held (Sätzler et al., 2002). It has been shown that release probability of vesicles within the calyx is heterogeneous ( $\mathrm{Wu}$ and Borst, 1999; Sakaba and Neher, 2001), although the contribution of a heterogeneity of release probability between active zones to the overall heterogeneity is not yet known. We therefore tested in 18 terminals, each containing between 3 and 11 visually identified clusters of between 20 and 130 vesicles, whether the percentage of photoconverted vesicles differed between the clusters of the same terminal. These terminals had been stimulated by $1,3,15$, or 30 min high $\mathrm{K}^{+}$solution in the presence of FM1-43, with overall labeling efficiencies ranging between 3 and $36 \%$. The differences between the clusters were not significantly different $\left(\chi^{2}\right.$ test; $p>$ 0.05 after Bonferroni correction), suggesting that the different release sites behaved similarly during stimulation with high $\mathrm{K}^{+}$ solution.

\section{Large endosomal-like structures}

After stimulation with high $\mathrm{K}^{+}$solution in the presence of styryl dyes, we observed an increase in large endosomal-like structures; however, these structures generally did not contain any photoconverted label. To investigate whether these structures were endocytotic, we repeated these experiments using HRP as an endocytotic marker. When slices were fixed directly after stimulating for 3 min with high $\mathrm{K}^{+}$solution in the presence of HRP, the calyx of Held contained numerous HRP-labeled endosome-like structures (Fig. 3A). To a large extent, these structures appear as round vacuole-like structures, similar to some of the HRP-labeled cisternas described originally by Heuser and Reese (1973). More rarely we observed flattened cisterna-like structures (Fig. 3B), similar to the structures that were observed in the frog neuromuscular junction when labeling with FM1-43 (Richards et al., 2000). It is possible that the difference between the two structures is caused by an osmotic effect induced by the high $\mathrm{K}^{+}$labeling or by the fixatives, although this possibility was not investigated further. On the basis of three-dimensional reconstructions of these endosomal-like structures from three to nine consecutive EM sections in a dozen terminals, we found no evidence that these structures were connected to each other or to the plasma membrane (data not shown). After return to control solution, the large structures disappeared (Fig. 3C, left panel), while, at the same time, the number of labeled vesicles increased significantly (Fig. $3 C$, middle panel) $(p<0.005)$. The disappearance of the large structures and increase in the number of labeled vesicles were slow processes, with half-times of $\sim 10 \mathrm{~min}$.

On average, vesicles in the recycling pool may be closer to the membrane compared with the vesicles that do not contribute to release (Schikorski and Stevens, 2001). We tested whether the mean distance of a vesicle to the plasma membrane facing the synaptic cleft differed between vesicles that were photoconverted and vesicles that had a clear lumen for terminals that had been stimulated for $3 \mathrm{~min}$ with high $\mathrm{K}^{+}$solution in the presence of $\mathrm{RH} 414$. In the terminals that were fixed directly, the distance of positive vesicles to the plasma membrane was on average $\sim 20 \%$ larger than that of negative vesicles $(p<0.01$; confidence interval $6-40 \%)$, whereas this distance did not differ significantly in slices that had rested for at least $10 \mathrm{~min}$ (Fig. $1 \mathrm{D}$ ). We conclude that labeled vesicles were not preferentially oriented near the membrane facing the postsynaptic cell.

Vesicle depletion

In slices that were fixed immediately after $3 \mathrm{~min}$ stimulation in high $\mathrm{K}^{+}$solution in the presence of HRP or RH414, the vesicle density in the calyx of Held was significantly lower $(7.3 \pm 0.5$ vesicles per micrometers of plasma membrane facing the principal cell; $n=5$ animals, 15 terminals; $p<0.05$ ) (Fig. $3 C$, right panel) than in terminals of slices that had recovered for at least 15 min $(17.3 \pm 1.6 ; n=9$ animals, 38 terminals $)$ or in terminals of slices that had not been stimulated $(16.9 \pm 1.6 ; n=3$ slices, 8 terminals). Similar results were obtained if the vesicle density was quantified as the number of vesicles per terminal area.

\section{Afferent stimulation}

Stability of synaptic transmission during stimulation at $5 \mathrm{~Hz}$

We conclude that a 3 min stimulation with high $\mathrm{K}^{+}$solution led to major changes in the terminal. Immediately after the stimulus, the number of vesicles was significantly lower, and a large number of endosome-like structures appeared, which over a period of many minutes disappeared, while at the same time vesicles reappeared. The slow time course of both the disappearance of the endosome-like structures and the appearance of new vesicles raises the question: what is the functional relevance of this vesicle recycling pathway? To answer this question, we first investigated how well the terminal can sustain its output during prolonged firing at different presynaptic action potential frequencies. After a few stimuli at a frequency of $5 \mathrm{~Hz}$, the amplitudes reached a new average level, in agreement with earlier results (for review, see von Gersdorff and Borst, 2002). At this frequency, depression is presynaptic. Previously, the depression had only been studied for brief trains. To test whether under these conditions there is a slower component to the depression during stimulation at $5 \mathrm{~Hz}$, which could be attributed to the depletion of the reserve pool, we prolonged the stimulation to at least $10 \mathrm{~min}$. For the prolonged stimulation period, the amplitude of the EPSCs still remained stable. Final level was $-0.8 \pm 0.1 \mathrm{nA}$, a decrease of $62 \pm 6 \%$ from the amplitude of the first EPSC in the train, which was $-2.9 \pm 0.8$ $\mathrm{nA}$, but similar to the level reached after five stimuli $(n=11)$ (Fig. $4 A, B)$. 
In contrast, at a stimulus frequency of $20 \mathrm{~Hz}$, the amplitude of the EPSCs gradually decreased (Fig. 4C,D). A gradual change in the shape of the presynaptic action potential contributed to the slow decrease in the size of the EPSCs, as suggested from a change in the prespike [the capacitatively coupled presynaptic action potential that can be recorded in the postsynaptic cell (Forsythe, 1994)].

\section{Release probability during stimulation} at $5 \mathrm{~Hz}$

The stability of the size of the EPSCs during prolonged stimulation at $5 \mathrm{~Hz}$ suggests that the size of the different participating vesicle pools is stable after the first APs. To get an estimate of the probability of release of vesicles in the recycling pool under these conditions, we labeled terminals with the styryl dye RH414, and after a recovery period of at least $20 \mathrm{~min}$ in the absence of the dye, we studied fluorescence destaining during afferent stimulation at $5 \mathrm{~Hz}$ (Fig. 5). In 6 of 12 experiments, after 15 min of stimulation, at least $80 \%$ of the fluorescence of the terminal had disappeared. In the other terminals, including two terminals that were preloaded with high $\mathrm{K}^{+}$solution instead of $5 \mathrm{~Hz}$ afferent stimulation, destaining ranged between 35 and $70 \%$. The time course of destaining during the first 15 min could generally be well described by a single exponential function, even if longer stimulation resulted in additional destaining (Fig. 5A,B); its time constant was $260 \pm 30 \mathrm{sec}(n=12)$ (Fig. $5 C$ ). For an exponential process, the mean time before destaining of a fluorescent vesicle equals the time constant. At $5 \mathrm{~Hz}$, a time constant of $260 \mathrm{sec}$ corresponds to $\sim 1000$ stimuli. The destaining experiments therefore suggest that the probability that an action potential will release a fluorescently labeled vesicle is $\sim 0.1 \%$ at $5 \mathrm{~Hz}$ for the majority of labeled vesicles. The presence of residual staining in most experiments suggested that in addition some vesicles had a much lower release probability.

We also tested destaining at $20 \mathrm{~Hz}$. At this frequency, the EPSC amplitudes were not stable (Fig. 4C,D) and delayed release and postsynaptic receptor desensitization are more pronounced (von Gersdorff and Borst, 2002), making a quantitative analysis of release probabilities difficult. In one experiment the EPSCs ran down rapidly. The other four terminals destained to $>90 \%$ with a time constant ranging between 35 and $100 \mathrm{sec}$. This shows that destaining is frequency dependent and that the destaining time constant during $5 \mathrm{~Hz}$ stimulation was most likely not limited by slow diffusion of dye out of the slice.

\section{Variability of quantal content}

Quantal content was rather variable between experiments; on average it was $21 \pm 3(n=12)$ when stimulating at $5 \mathrm{~Hz}$. To be able to relate the time course of destaining and the quantal con-
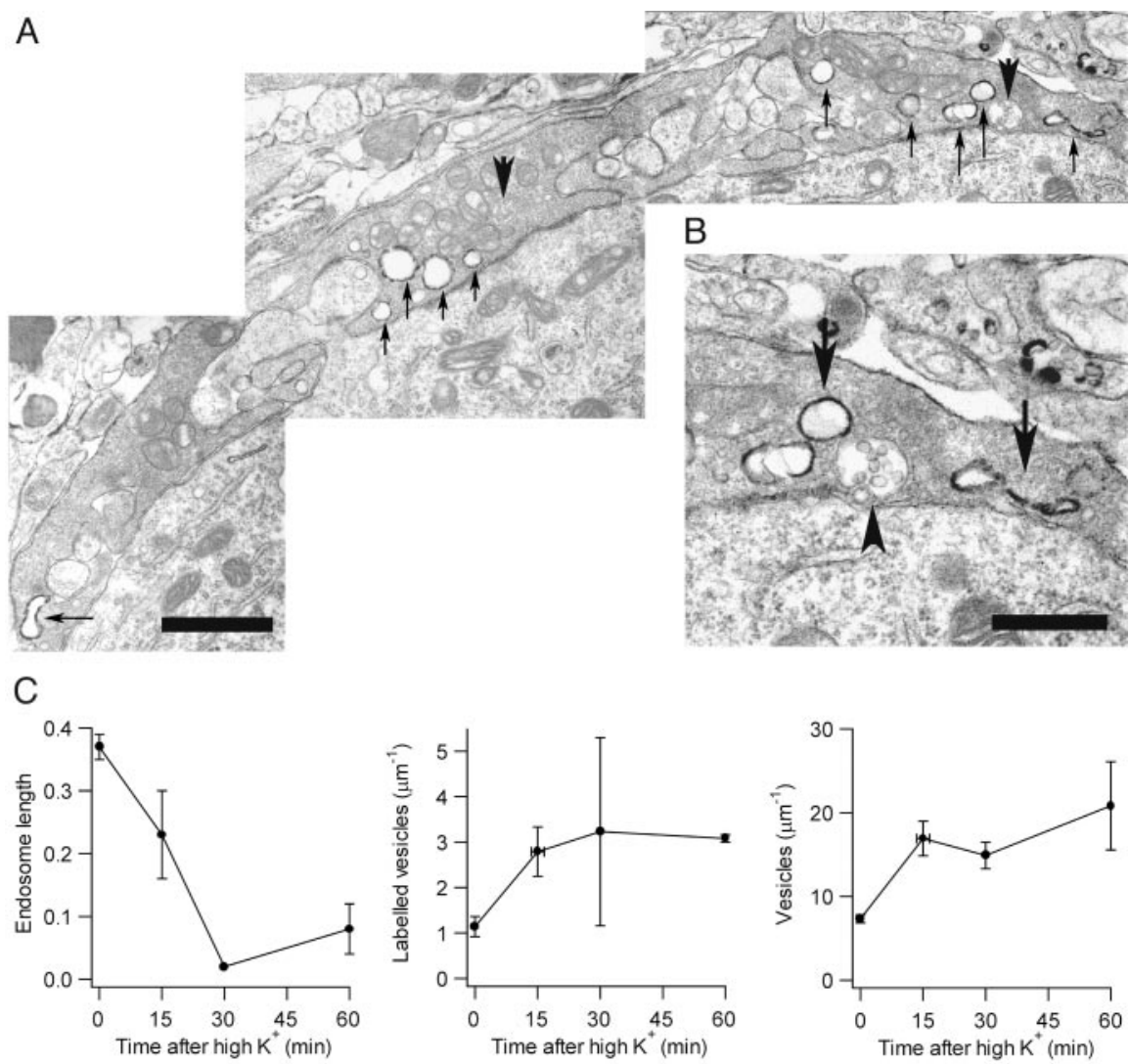

Figure 3. Vesicle recycling through endosomal intermediates. $A$, Labeling endosomal intermediates with HRP. Ultrastructure of terminal after direct fixation after labeling for $3 \mathrm{~min}$ in high $\mathrm{K}^{+}$solution with HRP. A sizeable number of large structures that 列 they would be cisternum-like (most right arrow). Also note the presence of multivesicular bodies (arrowheads), which were in high $\mathrm{K}^{+}$solution containing HRP. The large endosome-like structures were contoured, and their membrane length was expressed relative to the length of the presynaptic membrane facing the synaptic cleft within the same sections. Middle panel, Increase of the number of labeled vesicles has a similar time course as the decrease in endosome-like structures. Slices were ( 0 min, $n=5$ animals, 15 terminals; $10-20$ min, $n=5$ animals, 26 terminals; 30 min, $n=2$ animals, 7 terminals; $60 \mathrm{~min}, n=2$ animals, 5 terminals). Right panel, The total number of SVs in the terminal relative to the length of the presynaptic membrane facing the synaptic cleft in the same sections is significantly lower $(p<0.05)$ directly after stimulation ( 0 min) than after $10-60$ min rest (same animals and terminals as in middle panel).

tent, we further investigated the source of this variability. The large variability of quantal content during stimulation at $5 \mathrm{~Hz}$ between experiments could be attributable to either a higher average release probability at release sites or a larger number of release sites in the experiments in which we observed a larger quantal content. The lack of a significant correlation between the destaining time constant and the quantal content (Fig. 5C) ( $p=$ 0.79 ) suggested that a connection with a large quantal content did not have a larger release probability at individual release sites. The destaining time constant is only an indirect measure, however, for release probability at individual release sites; therefore, we also measured the rate of block of synaptic NMDA currents by the use-dependent NMDA-type glutamate receptor channel blocker MK-801 (Fig. 6A). Because this drug blocks NMDA channels only when they are open, their rate of block is a measure for release probability (Hessler et al., 1993; Rosenmund et al., 1993; Iwasaki and Takahashi, 2001). Principal cells were voltage 
A

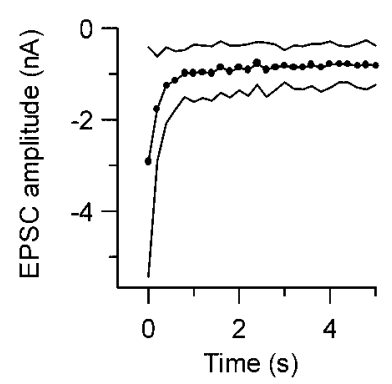

C

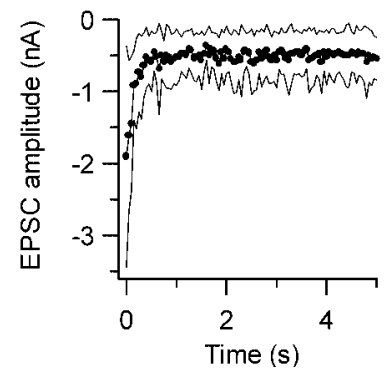

B

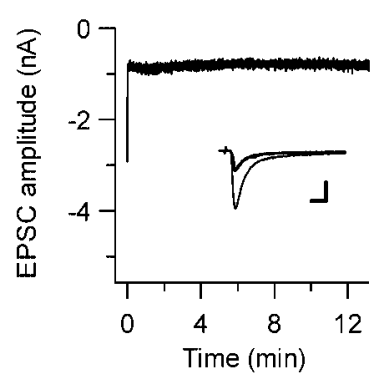

D

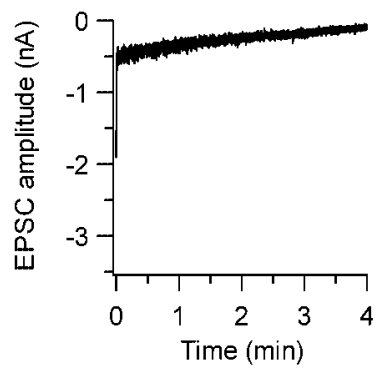

A
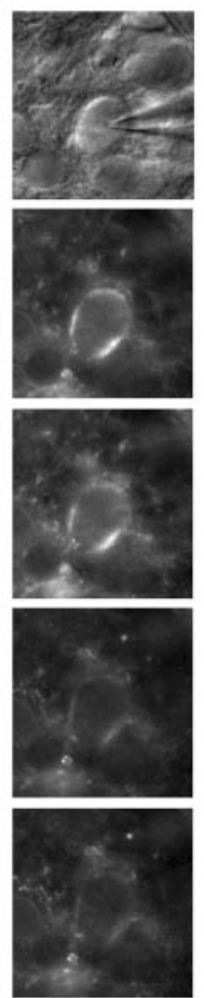

B
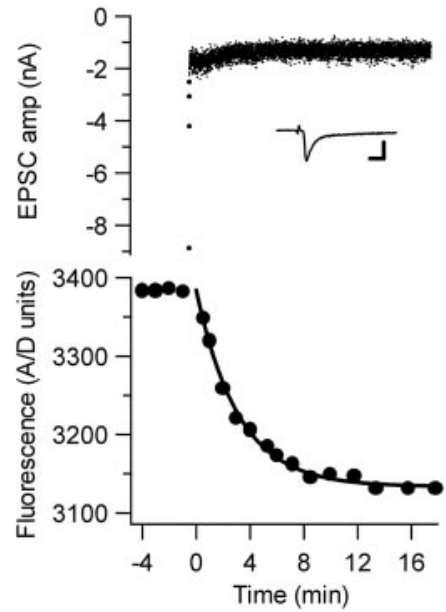

C

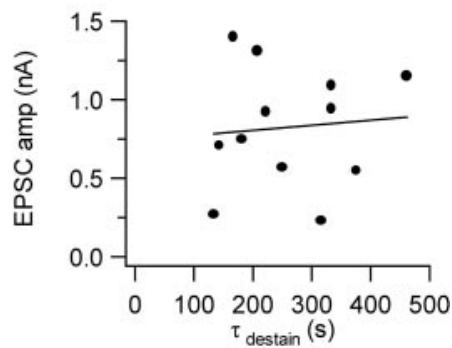

Figure 4. Stability of synaptic transmission at $5 \mathrm{~Hz}$ and $20 \mathrm{~Hz}$. A, Average amplitude of EPSC $(n=11)$ during $5 \mathrm{~Hz}$ stimulation. Solid lines denote mean \pm 1 SD. $B$, Same as $A$ at lower time resolution. Inset shows sample EPSC at $0,1,5,10$, and 20 min stimulation of one of the synapses overlaid. Horizontal calibration, $2 \mathrm{msec}$; vertical, $1 \mathrm{nA}$. Stimulation artifact has been blanked. $C$, Average amplitude of EPSCS $(n=5)$ during $20 \mathrm{~Hz}$ stimulation. Solid lines denote mean \pm 1 SD. $D$, Same as (at lower time resolution.

clamped at $+60 \mathrm{mV}$ to increase the NMDA component of the EPSC. EPSCs were scaled to the peak of the fast component of the EPSC, which is caused by current through AMPA-type glutamate receptors (Forsythe and Barnes-Davies, 1993) to reduce variability introduced by variability in the amount of release. The EPSCs at the end of the experiment, when NMDA channels were fully blocked, were used to subtract the AMPA-type component from all EPSCs (Fig. $6 \mathrm{~B}$ ). At $0.1 \mathrm{~Hz}$, the decrease in the NMDA current in the presence of MK-801 ( $5 \mu \mathrm{M})$ was well described by a single exponential function (Fig. 6C) with a time constant of $200 \pm 35$ $\sec (n=10)$. The size of the EPSC at $-80 \mathrm{mV}$ under control conditions measured at 0.1 or $5 \mathrm{~Hz}$ and the time constant of block were not significantly correlated (Fig. 6D) $(p=0.27)$. Similar results were obtained in a separate series of experiments in which the stimulation frequency during MK-801 block was $5 \mathrm{~Hz}$ instead of $0.1 \mathrm{~Hz}$. During $5 \mathrm{~Hz}$ stimulation the time constant of block was $11 \pm 0.9 \sec (n=6)$, but the rate of block again was not correlated to the amplitude of the AMPA-type EPSCs at 0.1 or $5 \mathrm{~Hz}$ under control conditions ( $p=0.22$; data not shown). The lack of a significant correlation between both destaining time constant and EPSC size and between rate of block by MK-801 and EPSC size suggests that synapses with large EPSCs had a larger number of release sites and a larger total size of the recycling pool of vesicles, rather than a higher release probability or larger size of the recycling pool per individual release site.

Photoconversion of fluorescently labeled identified terminals If the probability that a fluorescent vesicle will be released is 1 in 1000 and each action potential releases $\sim 20$ vesicles, it is tempting to conclude that the total recycling pool is equal to 20,000 synaptic vesicles ( $\sim 10 \%$ of the total number of vesicles); how-

Figure 5. Destaining of terminals labeled with $\mathrm{RH} 414$ during prolonged stimulation at $5 \mathrm{~Hz}$. $A$, Images of terminal. Top image, Infrared differential interference contrast image. Other images, Fluorescence images, taken (from top to bottom) 1 min before and 2, 16, and 30 min after start of afferent stimulation. Scale bar, $10 \mu \mathrm{m}$. B, Top panel, Amplitudes of EPSCs during stimulation at $5 \mathrm{~Hz}$. Inset, Sample EPSC. Calibration: $2 \mathrm{msec}, 1 \mathrm{nA}$. Stimulation artifact has been blanked. Bottom panel, Decrease in average fluorescence of the terminal during stimulation. Fluorescence values have been corrected for bleaching. Time 0 denotes the start of stimulation. Solid line is the fit of fluorescence decrease with an exponential function with a time constant of $170 \mathrm{sec}$. Data in $A$ and $B$ are from the same terminal. C, Relation between the time constant of the fit of the fluorescence decrease during afferent stimulation at $5 \mathrm{~Hz}$ with an exponential function ( $\tau_{\text {destain }}$ ) and the average amplitude of the EPSCs $(n=12)$. Solid line is the regression line, showing a lack of a significant correlation (slope $20 \mathrm{pA} / \mathrm{min} ; r=0.09$ ) between EPSC size and $\tau_{\text {destain }}$.

ever, this calculation presupposes that the probability that a fluorescent vesicle is released is not different from the average probability of vesicles of the recycling pool. The recycling pool can be visualized by photoconversion after labeling with a fluorescent dye. In Figure 5, it was shown that stimulating synapses for 20 $\min$ at $5 \mathrm{~Hz}$ was sufficiently long to destain them. We therefore labeled synapses at $5 \mathrm{~Hz}$ for $20 \mathrm{~min}$, in the presence of RH414 (Fig. 7). Because of the uncertainty on the one hand of how long it takes before vesicle formation is complete (Fig. 3) and on the other hand the possibility that labeled vesicles are released during a rest period after stimulation, we photoconverted in separate experiments immediately after stimulation or after a rest period of $30 \mathrm{~min}$. Fluorescence of the stimulated terminals was generally weak. An example of the fluorescence image of a calyx that was stimulated for $20 \mathrm{~min}$ at $5 \mathrm{~Hz}$ and rested for $30 \mathrm{~min}$ before fixation is shown in Figure 7B. Because the postsynaptic cell was filled with HRP via a whole-cell recording before RH414 labeling, we were able to retrieve the synapse after fixation and photoconversion of the fluorescent vesicles (Fig. 7C; $A-D$ are from the same terminal). The fraction of labeled vesicles was not very large, neither immediately after fixation $(0.6 \pm 0.3 \mathrm{SV} / \mu \mathrm{m}$ or $3.3 \pm$ 
A

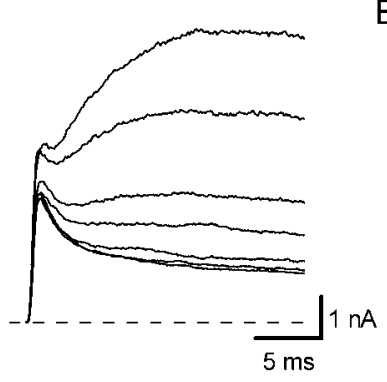

B

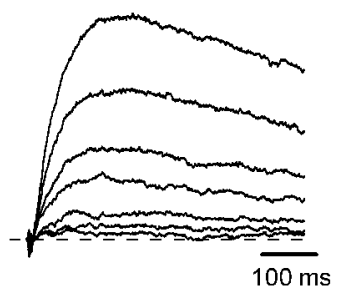

C

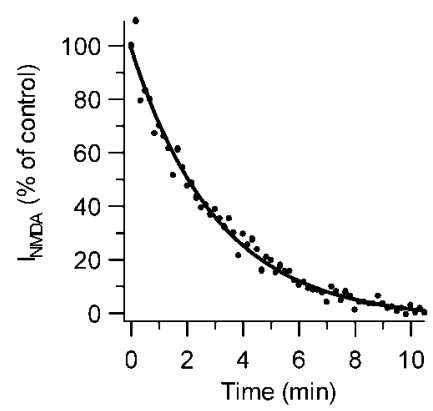

$\mathrm{D}$

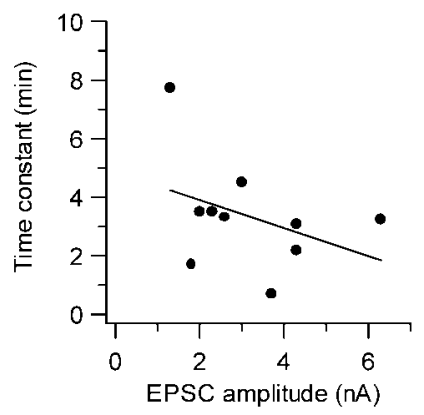

Figure 6. Block of NMDA-type glutamatergic synaptic transmission by open channel blocker MK-801 during low-frequency stimulation. A, Synaptic currents in a principal cell during afferent stimulation at $0.1 \mathrm{~Hz}$ in the presence of MK-801 $(5 \mu \mathrm{M})$. Every 10th stimulus is shown, starting with the first stimulus. Holding potential was $+60 \mathrm{mV}$. Current consisted of a rapid outward current through AMPA-type glutamate receptors, followed by a slower component mediated by NMDA-type glutamate receptors. $B$, Isolation of the MK-801-sensitive NMDA component by subtraction of the rapid AMPA-type currents. Before subtraction, currents in $A$ were scaled to have the same rapid peak component to reduce the influence of synaptic depression. Note the difference in time scale between $A$ and $B$. C, Decay of the MK-801-sensitive NMDA current. Same experiment as in $A$ and $B$. Solid line is the fit of the data with an exponential function with a time constant of $3 \mathrm{~min}$. D, Relation between the time constant of the block of the NMDA currents during afferent stimulation at $0.1 \mathrm{~Hz}$ and the average amplitude of the initial NMDA currents measured before application of MK-801 ( $n=10$ synapses; 7 animals). Solid line is the regression line $(r=-0.38 ; p>0.05)$.

$1.2 \% ; n=3$ ) (Fig. $7 E)$ nor after a 30 min rest period (1.6 \pm 0.6 $\mathrm{SV} / \mu \mathrm{m}$ or $4.6 \pm 1.2 \% ; n=4)$. For comparison, we also assessed the effect of the same number of action potentials, but at a higher stimulation frequency, i.e., $5 \mathrm{~min}$ at $20 \mathrm{~Hz}$. In destaining experiments this protocol was sufficient to almost fully destain most terminals. Nevertheless, again the labeled fraction was rather low, both directly after fixation $(0.6 \pm 0.2 \mathrm{SV} / \mu \mathrm{m}$ or $5.9 \pm 1.0 \% ; n=$ 3 ) and after 30 min of recovery in Ringer's solution containing Advasep $(0.9 \pm 0.5 \mathrm{SV} / \mu \mathrm{m}$ or $6.0 \pm 2.3 \% ; n=4)$. The average number of labeled vesicles was not significantly different among the four groups. In the two groups that were directly fixed after stimulation, photoconverted vesicles were on average $\sim 30 \%$ farther away from the membrane than control vesicles $(p<0.01$; confidence interval $13-58 \%)$. After 30 min recovery, photoconverted vesicles were still $\sim 20 \%$ farther away $(p<0.01$; confidence interval 6-36\%).

The low labeling was not caused by smaller EPSCs in the identified terminals than in the terminals in which destaining was studied, because the amplitudes in these two types of experiments were not significantly different, both at low frequency and during $5 \mathrm{~Hz}$ trains.

Finally, we compared the average number of labeled vesicles in the identified terminals that were stimulated with afferently evoked action potentials with slices that were stimulated by high

A

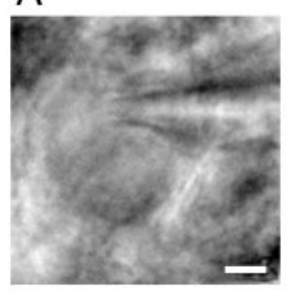

B

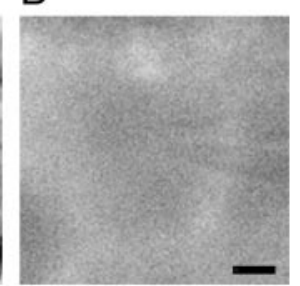

C

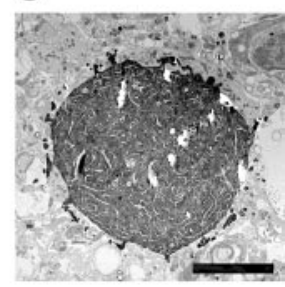

D

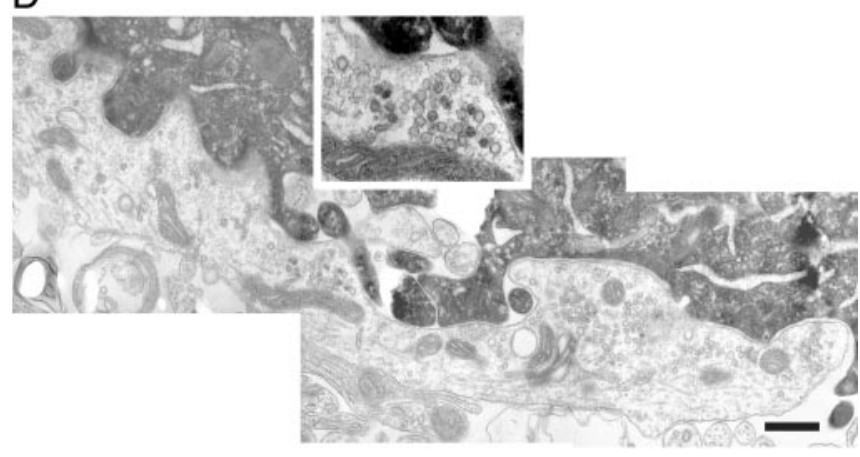

E

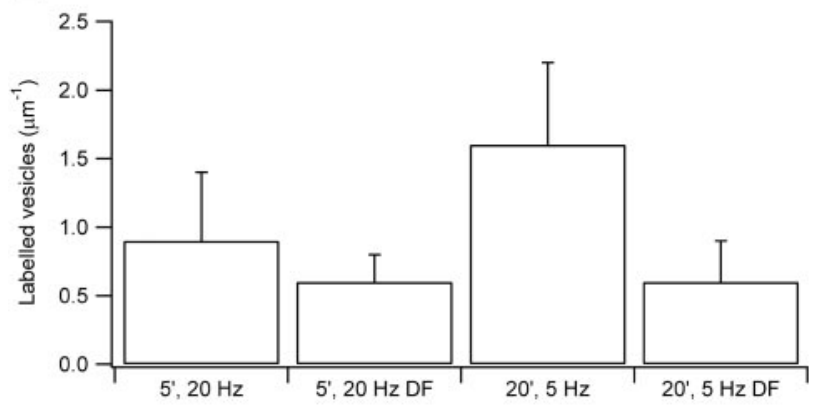

Figure 7. Labeling synaptic vesicles with RH414 in identified terminals with afferent stimulation. A, Differential interference contrast video image of principal cell with patch pipette. $B$, Fluorescence image showing weak fluorescent staining of the calyx after afferent stimulation. $C$, EM overview of principal cell showing HRP staining. D, EM detail showing the terminal, with labeled and unlabeled vesicles (inset). In this calyx-type terminal, $1.1 \mathrm{SV} / \mu \mathrm{m}$ plasma membrane facing the synaptic cleft were labeled, or 17 of 259 vesicles $(6.2 \%)$. $A-D$ are from the same cell. Scale bars: $A-C, 5 \mu \mathrm{m} ; D, 0.5 \mu \mathrm{m}$. E, Labeling for all stimulation conditions. DF, Directly fixed after stimulation. See Results for details.

$\mathrm{K}^{+}$solution (Fig. 2). The labeling in the identified terminals was not significantly different from the labeling in the slices that had been exposed for $1 \mathrm{~min}$ to high $\mathrm{K}^{+}$solution but differed from the 3,15 , and 30 min groups $(p<0.05$; post hoc Newman-Keuls test).

\section{Discussion}

Two modes of vesicle recycling

The calyx of Held has at least two different recycling modes. During afferent stimulation at $5 \mathrm{~Hz}$, a limited number of vesicles recycle, most likely without an endosomal intermediate. After depolarization of the terminal in high $\mathrm{K}^{+}$solution, we observed a recycling pathway characterized by the appearance of large endosome-like structures, from which synaptic vesicles appeared to form only slowly.

Our observations indicate that depolarizing terminals with high $\mathrm{K}^{+}$solution represented a massive stimulation. The total number of vesicles was significantly decreased, and numerous HRP-labeled endosome-like structures were observed directly after stimulation, with a total membrane length equaling almost 
$40 \%$ of the length of the plasma membrane that faced the postsynaptic cell (Fig. 3). Forty percent of the total surface of the calyx membrane facing the synaptic cleft $\left(1000 \mu \mathrm{m}^{2}\right.$ ) (Sätzler et al., 2002) is enough to give rise to 60,000 SVs with an average diameter of $46 \mathrm{~nm}$. Large membrane invaginations that pinch off to form endosome-like structures and eventually new vesicles have been described previously (Koenig and Ikeda, 1996; Takei et al., 1996; Gad et al., 1998; Marxen et al., 1999; Richards et al., 2000; Teng and Wilkinson, 2000; Leenders et al., 2002; Lenzi et al., 2002; Holt et al., 2003). Recycling of released vesicles, most likely via budding from the HRP-labeled endosomes that disappeared concomitantly, took minutes (Fig. 3B). This mode of vesicle recycling is so slow (Pysh and Wiley, 1974; Model et al., 1975; Marxen et al., 1999) that it is not expected to play a significant role in maintaining the RRP during normal transmission, because it will easily become the limiting step in the vesicle cycle (Lenzi et al., 2002). We hypothesize that the observed bulk endocytosis could serve as an emergency mechanism to keep the presynaptic membrane area that faces the postsynaptic cell within bounds.

Afferent stimulation at $5 \mathrm{~Hz}$ appeared to be a much milder stimulus. Vesicle replenishment could keep up with vesicle release; the synapse maintained its output for long periods (Fig. $4 B$ ), and no vesicle depletion was observed. Both optical and electrical techniques suggest a dominant role for rapid endocytosis with a time constant between 0.5 and $7.5 \mathrm{sec}$ both at the calyx of Held (Sun et al., 2002) and at other synapses (von Gersdorff and Matthews, 1994; Moser and Beutner, 2000; Sankaranarayanan and Ryan, 2001; Aravanis et al., 2003; Hallermann et al., 2003). Stronger stimulation leads to a slowing down of endocytosis (von Gersdorff and Matthews, 1994; Moser and Beutner, 2000; Sun et al., 2002), presumably because of saturation of the capacity of the endocytotic machinery (Sankaranarayanan and Ryan, 2001). Our data agree with these findings and suggest that during $5 \mathrm{~Hz}$ stimulation, the capacity of the machinery for rapid endocytosis is sufficient to meet demands. A quantal content of 20 (see Results) and 550 active zones (Sätzler et al., 2002) translates to endocytosis of $<0.2 \mathrm{SVs}$ per second per active zone. This fits both the rate of endocytosis after high-frequency stimulation (Sun et al., 2002) and the rate of recovery from synaptic depression (von Gersdorff et al., 1997) in the calyx of Held. It is also well within the estimated maximal endocytotic capacity of $1 \mathrm{SV}$ per second per active zone (Sankaranarayanan and Ryan, 2001) in hippocampal terminals, where the maximum replenishment rate is $\sim 0.25 \mathrm{SV}$ per second per bouton during prolonged stimulation (Wesseling and Lo, 2002). We propose that during high $\mathrm{K}^{+}$stimulation the endocytotic machinery is overwhelmed and that the slowing down of the endocytotic time constant in capacitance measurements reflects not only the limited capacity of this machinery but also the formation and pinching off of large membrane invaginations.

Although it was clear that the slow recycling mode via endosome-like intermediates was important during stimulation with the high $\mathrm{K}^{+}$solution, endosome-like structures are not likely to make a great contribution to the recycling during lowfrequency afferent stimulation, because the number of labeled vesicles did not increase significantly after a $30 \mathrm{~min}$ rest period after stimulation (at 5 or $20 \mathrm{~Hz}$ ), as compared with directly after stimulation. Most likely, this lack of increase was not caused by dye escape from endosome-like structures that retained a connection to the extracellular fluid, because similar results were obtained in preliminary experiments in which terminals were labeled with FM1-43 (data not shown), which does not escape from cisterna-like structures in the neuromuscular junction (Richards et al., 2000). Because the endosome-like structures were generally not photoconverted, however, their participation in vesicle recycling during afferent stimulation cannot be excluded. As unremarkable as the demands on the recycling machinery were at $5 \mathrm{~Hz}$, we did observe that at a frequency of $20 \mathrm{~Hz}$ the synapses generally showed AP failures during prolonged stimulation. Although we cannot definitively determine to what extent the terminals used this recycling mode during afferent stimulation, the failure of the terminal to sustain transmission at $20 \mathrm{~Hz}$ suggests that the APs fail before the endocytotic machinery does. Repeating these experiments using HRP as a fluid phase marker, transferring the slices to dye-containing Ringer's after stimulation (Richards et al., 2000), or trying other stimulation paradigms (tetanic bursts, for example) could be helpful to further delineate the contribution of bulk endocytosis to the vesicle cycle at the calyx of Held during afferent stimulation.

\section{Size of the recycling pool}

The combination of fluorescence destaining, release measurements, and electron microscopy permits an estimate of the size of the recycling pool in the calyx of Held. When stimulating with high $\mathrm{K}^{+}$solution for $15 \mathrm{~min}, 40 \%$ of the vesicles in the calyx terminals were labeled (Fig. 2), similar to observations in calyx terminals of the ciliary ganglion after prolonged stimulation (Nguyen and Sargent, 2002). As discussed above, however, the use of high $\mathrm{K}^{+}$solution provides a massive stimulus, and many of the labeled vesicles are expected to have a low release probability during afferent stimulation. As a first approximation, the ratio between quantal content and release probability of fluorescent vesicles gives a better indication of the size of the recycling pool. At $5 \mathrm{~Hz}$, the release probability of fluorescent vesicles was $\sim 0.1 \%$ and quantal content $\sim 20$, yielding a recycling pool of $\sim 20,000$ vesicles. This is only $\sim 10 \%$ of the total number of vesicles (see Results) and only $\sim 10$ times the size of the readily releasable pool in the calyx (Schneggenburger et al., 2002). This calculation assumes that the release probability of the vesicles labeled during stimulation is not different from the average release probability of the vesicles in the recycling pool. To address this question, we labeled the terminals using afferent stimulation for $20 \mathrm{~min}$ at 5 $\mathrm{Hz}$, which should theoretically be more than sufficient to label the recycling pool. The labeled fraction was somewhat lower than expected; only $5 \%$ (and hence the recycling pool $\sim 10,000$ vesicles). Several factors could contribute to the observed difference. Sun et al. (2002) recently observed that spontaneous vesicle fusion at the calyx of Held was followed by very rapid endocytosis taking $\sim 100 \mathrm{msec}$. As rapid as this form of endocytosis is, it is probably still slow enough to permit staining of the membrane before endocytosis is complete (Stevens and Williams, 2000; Zenisek et al., 2002), especially because the affinity of RH414 for membranes is lower than that of FM1-43. In addition, although photoconversion is a somewhat capricious technique, we did observe photoconversion of vesicles after $10 \mu \mathrm{M}$ RH414 dye exposure (data not shown), 10-fold lower than the concentration actually used during the experiments, suggesting that photoconversion efficiency was high in our experiments but perhaps still not 100\%. Incomplete staining as a result of too rapid endocytosis therefore is probably not a major cause of the low fraction of photoconverted vesicles after afferent stimulation. We also do not think that spontaneous release of labeled vesicles during the $30 \mathrm{~min}$ waiting period contributed greatly to a lower than expected labeling, because we did not find a difference in labeling between terminals that were fixed directly after labeling and those that rested for $30 \mathrm{~min}$ before fixation. Because our 
total vesicle number estimate $(188,000)$ is much higher than an earlier estimate $(77,000)$ (Sätzler et al., 2002), our recycling pool estimate might also be generous. The presence of vesicles that did not readily destain in half of the terminals suggests that these estimates of the recycling pool may be contaminated by the resting pool as well. Despite reservations about the exact numbers, it is clear that only a small fraction of the vesicles (5-10\%) participate in the recycling during continuous low-frequency stimulation. This must be caused by preferential release of vesicles that have been recently endocytosed, which has the effect of considerably reducing the necessary recycling pool (Harata et al., 2001b; Sara et al., 2002). Statistical analysis of vesicle distributions showed that photoconverted vesicles were on average farther away from the plasma membrane than unlabeled vesicles both after afferent stimulation and directly after high $\mathrm{K}^{+}$stimulation, but not after high $\mathrm{K}^{+}$simulation and subsequent rest. The difference in subcellular location seems to be insufficient, however, to account for their different release probability, so apparently vesicles that are formed by rapid endocytosis are tagged for re-release, whereas this is not the case for vesicles that were formed from endosomal-like structures.

\section{Variability in release probabilities between release sites and terminals}

Between experiments, we observed a large variability in quantal content during stimulation at $5 \mathrm{~Hz}$ (Fig. $5 C$ ). For most stimulation conditions, the different release sites at the calyx of Held show little interaction (for review, see Schneggenburger et al., 2002; Meinrenken et al., 2003). The variability in active zone size and in the number of docked vesicles at active zones (Sätzler et al., 2002) suggests that release probability may differ substantially between release sites; however, three independent observations suggest that the difference in quantal content between terminals is mainly caused by a difference in the number of release sites, rather than in their average release probability. Vesicle clusters did not differ significantly in labeling efficiency within the same terminal, which suggests that the recycling pool functions similarly between release sites. In addition, both the rate of block with MK-801 and the destaining time constant were less variable between experiments than the quantal content. Because both are a measure for release probability, we conclude that a difference in the number of release sites is a more important determinant of synaptic strength in the calyx than differences in the release probability at individual release sites.

\section{Is the vesicle cycle of the calyx of Held special?}

The calyx of Held synapse is generally seen as a rapid, fail-safe auditory relay [but see Kopp-Scheinpflug et al. (2003)]. Here the terminal typically failed during prolonged $20 \mathrm{~Hz}$ stimulation. An increase in vesicle pool size accompanied by a decrease in release probability later during development will presumably aid the synapses to follow higher frequencies than in the young animals that we recorded from (Taschenberger et al., 2002). Nevertheless, it is meaningful to compare synaptic transmission in the immature calyx with cultured hippocampal terminals or the neuromuscular junction to determine whether the calyx is specially adapted for auditory signaling. The vesicle cycle of the calyx shared with both other types of terminals the use of a rather limited recycling pool during low-frequency stimulation, with high $\mathrm{K}^{+}$solution being a much more effective stimulus for labeling vesicles (Harata et al., 2001b; Richards et al., 2003). In some respects the calyx was more similar to the frog neuromuscular junction, such as in release probability at low frequency $(0.1 \%)$ (Betz et al., 1992) versus 0.5\% in hippocampus (Ryan and Smith,
1995) or in its susceptibility to vesicle depletion. After massive stimulation there is less depletion in hippocampal boutons (Sara et al., 2002) than in the neuromuscular junction (Richards et al., 2003). In the neuromuscular junction, on the other hand, a clear contribution of endosome-like structures was demonstrated at higher stimulation frequencies (Koenig and Ikeda, 1996; Teng and Wilkinson, 2000; Richards et al., 2003), whereas this is less conspicuous for the calyx or for hippocampal synapses (Harata et al., 2001b), although in both the calyx and hippocampal synapses high $\mathrm{K}^{+}$stimulation does lead to formation of endosome-like structures (Marxen et al., 1999).

In conclusion, the main adaptation of the calyx for its function as an auditory relay appears to be its large number of release sites; most other aspects of the vesicle cycle appear to be rather conventional.

\section{References}

Aravanis AM, Pyle JL, Tsien RW (2003) Single synaptic vesicles fusing transiently and successively without loss of identity. Nature 423:643-647.

Betz WJ, Mao F, Bewick GS (1992) Activity-dependent fluorescent staining and destaining of living vertebrate motor nerve terminals. J Neurosci 12:363-375.

Borst JGG, Sakmann B (1996) Calcium influx and transmitter release in a fast CNS synapse. Nature 383:431-434.

Forsythe ID (1994) Direct patch recording from identified presynaptic terminals mediating glutamatergic EPSCs in the rat CNS, in vitro. J Physiol 479:381-387.

Forsythe ID, Barnes-Davies M (1993) The binaural auditory pathway: excitatory amino acid receptors mediate dual time course excitatory postsynaptic currents in the rat medial nucleus of the trapezoid body. Proc Roy Soc Lond B Biol Sci 251:151-157.

Gad H, Löw P, Zotova E, Brodin L, Shupliakov O (1998) Dissociation between $\mathrm{Ca}^{2+}$-triggered synaptic vesicle exocytosis and clathrin-mediated endocytosis at a central synapse. Neuron 21:607-616.

Hallermann S, Pawlu C, Jonas P, Heckmann M (2003) A large pool of releasable vesicles in a cortical glutamatergic synapse. Proc Natl Acad Sci USA 100:8975-8980.

Harata N, Ryan TA, Smith SJ, Buchanan J, Tsien RW (2001a) Visualizing recycling synaptic vesicles in hippocampal neurons by FM 1-43 photoconversion. Proc Natl Acad Sci USA 98:12748-12753.

Harata N, Pyle JL, Aravanis AM, Mozhayeva M, Kavalali ET, Tsien RW (2001b) Limited numbers of recycling vesicles in small CNS nerve terminals: implications for neural signaling and vesicular cycling. Trends Neurosci 24:637-643.

Henkel AW, Lübke J, Betz WJ (1996) FM1-43 dye ultrastructural localization in and release from frog motor nerve terminals. Proc Natl Acad Sci USA 93:1918-1923.

Hessler NA, Shirke AM, Malinow R (1993) The probability of transmitter release at a mammalian central synapse. Nature 366:569-572.

Heuser JE, Reese TS (1973) Evidence for recycling of synaptic vesicle membrane during transmitter release at the frog neuromuscular junction. J Cell Biol 57:315-344.

Holt M, Cooke A, Wu MM, Lagnado L (2003) Bulk membrane retrieval in the synaptic terminal of retinal bipolar cells. J Neurosci 23:1329-1339.

Iwasaki S, Takahashi T (2001) Developmental regulation of transmitter release at the calyx of Held in rat auditory brainstem. J Physiol (Lond) 534:861-871.

Kay AR, Alfonso A, Alford S, Cline HT, Holgado AM, Sakmann B, Snitsarev VA, Stricker TP, Takahashi M, Wu L-G (1999) Imaging synaptic activity in intact brain and slices with FM1-43 in C. elegans, lamprey, and rat. Neuron 24:809-817.

Koenig JH, Ikeda K (1996) Synaptic vesicles have two distinct recycling pathways. J Cell Biol 135:797-808.

Kopp-Scheinpflug C, Lippe WR, Dorrscheidt GJ, Rübsamen R (2003) The medial nucleus of the trapezoid body in the gerbil is more than a relay: comparison of pre- and postsynaptic activity. J Assoc Res Otolaryngol 4:1-23.

Leenders AGM, Scholten G, de Lange RPJ, Lopes da Silva FH, Ghijsen WEJM (2002) Sequential changes in synaptic vesicle pools and endosome-like 
organelles during depolarization near the active zone of central nerve terminals. Neuroscience 109:195-206.

Lenzi D, Crum J, Ellisman MH, Roberts WM (2002) Depolarization redistributes synaptic membrane and creates a gradient of vesicles on the synaptic body at a ribbon synapse. Neuron 36:649-659.

Marxen M, Volknandt W, Zimmermann H (1999) Endocytic vacuoles formed following a short pulse of $\mathrm{K}^{+}$-stimulation contain a plethora of presynaptic membrane proteins. Neuroscience 94:985-996.

Meinrenken CJ, Borst JGG, Sakmann B (2003) Local routes revisited: the space and time dependence of the $\mathrm{Ca}^{2+}$ signal for phasic transmitter release at the rat calyx of Held. J Physiol (Lond) 547:665-689.

Model PG, Highstein SM, Bennett MVL (1975) Depletion of vesicles and fatigue of transmission at a vertebrate central synapse. Brain Res 98:209-228.

Moser T, Beutner D (2000) Kinetics of exocytosis and endocytosis at the cochlear inner hair cell afferent synapse of the mouse. Proc Natl Acad Sci USA 97:883-888.

Nguyen D, Sargent PB (2002) Synaptic vesicle recycling at two classes of release sites in giant nerve terminals of the embryonic chicken ciliary ganglion. J Comp Neurol 448:128-137.

Pysh JJ, Wiley RG (1974) Synaptic vesicle depletion and recovery in cat sympathetic ganglia electrically stimulated in vivo. Evidence for transmitter secretion by exocytosis. J Cell Biol 60:365-374.

Richards DA, Guatimosim C, Betz WJ (2000) Two endocytic recycling routes selectively fill two vesicle pools in frog motor nerve terminals. Neuron 27:551-559.

Richards DA, Guatimosim C, Rizzoli SO, Betz WJ (2003) Synaptic vesicle pools at the frog neuromuscular junction. Neuron 39:529-541.

Rosenmund C, Clements JD, Westbrook GL (1993) Nonuniform probability of glutamate release at a hippocampal synapse. Science 262:754-757.

Ryan TA, Smith SJ (1995) Vesicle pool mobilization during action potential firing at hippocampal synapses. Neuron 14:983-989.

Sakaba T, Neher E (2001) Quantitative relationship between transmitter release and calcium current at the calyx of Held synapse. J Neurosci 21:462-476.

Sankaranarayanan S, Ryan TA (2001) Calcium accelerates endocytosis of vSNAREs at hippocampal synapses. Nat Neurosci 4:129-136.

Sara Y, Mozhayeva MG, Liu X, Kavalali ET (2002) Fast vesicle recycling supports neurotransmission during sustained stimulation at hippocampal synapses. J Neurosci 22:1608-1617.
Sätzler K, Söhl LF, Bollmann JH, Borst JGG, Frotscher M, Sakmann B, Lübke JH (2002) Three-dimensional reconstruction of a calyx of Held and its postsynaptic principal neuron in the medial nucleus of the trapezoid body. J Neurosci 22:10567-10579.

Schikorski T, Stevens CF (2001) Morphological correlates of functionally defined synaptic vesicle populations. Nat Neurosci 4:391-395.

Schneggenburger R, Sakaba T, Neher E (2002) Vesicle pools and short-term synaptic depression: lessons from a large synapse. Trends Neurosci 25:206-212.

Stevens CF, Williams JH (2000) "Kiss and run" exocytosis at hippocampal synapses. Proc Natl Acad Sci USA 97:12828-12833.

Sun J-Y, Wu XS, Wu L-G (2002) Single and multiple vesicle fusion induce different rates of endocytosis at a central synapse. Nature 417:555-559.

Takei K, Mundigl O, Daniell L, De Camilli P (1996) The synaptic vesicle cycle: a single vesicle budding step involving clathrin and dynamin. J Cell Biol 133:1237-1250.

Taschenberger H, Leão RM, Rowland KC, Spirou GA, von Gersdorff H (2002) Optimizing synaptic architecture and efficiency for highfrequency transmission. Neuron 36:1127-1143.

Teng H, Wilkinson RS (2000) Clathrin-mediated endocytosis near active zones in snake motor boutons. J Neurosci 20:7986-7993.

Vischer NOE, Huls PG, Woldringh CL (1994) Object-Image: an interactive image analysis program using structured point collection. Binary 6:160-166.

von Gersdorff H, Borst JGG (2002) Short-term plasticity at the calyx of Held. Nat Rev Neurosci 3:53-64.

von Gersdorff H, Matthews G (1994) Dynamics of synaptic vesicle fusion and membrane retrieval in synaptic terminals. Nature 367:735-739.

von Gersdorff H, Schneggenburger R, Weis S, Neher E (1997) Presynaptic depression at a calyx synapse: the small contribution of metabotropic glutamate receptors. J Neurosci 17:8137-8146.

Wesseling JF, Lo DC (2002) Limit on the role of activity in controlling the release-ready supply of synaptic vesicles. J Neurosci 22:9708-9720.

Wu L-G, Borst JGG (1999) The reduced release probability of releasable vesicles during recovery from short-term synaptic depression. Neuron 23:821-832.

Zenisek D, Steyer JA, Feldman ME, Almers W (2002) A membrane marker leaves synaptic vesicles in milliseconds after exocytosis in retinal bipolar cells. Neuron 35:1085-1097. 